\title{
Clustering patterns of human papillomavirus infections among HIV-positive women in Kenya
}

Salvatore Vaccarella ${ }^{1}$, Hugo De Vuyst ${ }^{*}$, Nelly R Mugo ${ }^{2}$, Samah R Sakr ${ }^{3}$, Martyn Plummer ${ }^{1}$, Daniëlle A M Heideman ${ }^{4}$, Silvia Franceschi ${ }^{1}$ and Michael Chung ${ }^{5,6,7}$

\begin{abstract}
Background: HIV-positive women are at increased risk of human papillomavirus (HPV) infection, and, especially, multiple infections compared to HIV-negative women. Whether certain HPV types have a tendency to cluster in multiple infections beyond or below what would be expected by shared risk factors (e.g., sexual behavior and the degree of immunosuppression) is unclear. We, therefore, investigated clustering patterns of 44 HPV types in HIV-positive women from Kenya.

Findings: HPV status was assessed on cervical scrapings from 498 women using GP5+/6+ PCR and reverse line blot. Logistic regression was used to model type-specific HPV positivity, adjusted for age, specific HPV type prevalence, CD4, combination antiretroviral therapy, and, in the Full Model, individual-level random effects that represent unobservable risk factors common to all HPV types. We found a modest excess of women with co-infections with 2 HPV types (1.12; 95\% credible intervals: 1.03-1.21) in the Full Model but no significant associations of individual types. No significant deviations of observed/expected counts were observed for any 2-way combination of HPV types at either the chosen level of significance, $p=0.00005$, or at $p=0.01$. Findings were substantially similar when women with CIN2/3 were excluded and when they were stratified by use of anti-retroviral therapy or CD4 count.
\end{abstract}

Conclusions: HPV co-infections occurred at random in the cervix of HIV-positive women as previously found in HIV-negative women. The removal of HPV types through vaccination should not result, therefore, in an increase or decrease in the prevalence of HPV types not targeted by vaccination in immunosuppressed women.

Keywords: Human papillomavirus, HIV, Prevalence, Women, Multiple infections

\section{Findings Introduction}

HIV-positive women are at increased risk of infections with human papillomavirus (HPV) compared to HIVnegative women $[1,2]$. Although multiple HPV infections are particularly common in HIV-positive women, it is not clear whether certain HPV types have the tendency to cluster in multiple infections beyond or below what would be expected by shared risk factors, e.g., sexual behavior and the degree of immunosuppression. This could be relevant for the evaluation of the effects of HPV prophylactic vaccines. The removal of certain HPV types through vaccination could, in theory, indirectly

\footnotetext{
* Correspondence: devuysth@iarc.fr

${ }^{1}$ International Agency for Research on Cancer, 150 cours Albert Thomas, Lyon cedex 08 69372, France

Full list of author information is available at the end of the article
}

increase or decrease the prevalence of other untargeted types.

Previous studies among HIV-negative women [3-7] and men $[7,8]$ have reported a general tendency of HPV types to cluster in multiple infections. However, there has been no evidence for specific HPV types to be found together more or less often than expected by chance with other types. Significant excesses of a few HPV type combinations have been observed, but they have been demonstrated to derive from diagnostic artefacts, e.g., cross-hybridization of closely homologous HPV types using enzyme immunoassay for genotyping [8] or technical limitations of the HPV detection methods used, e.g., indirect measure of HPV52 by using a mixed probe using Roche Linear Array [3].

To date, the clustering patterns of multiple HPV infections in HIV-positive women have been evaluated in only one study based in the United States [9]. Chaturvedi et al.

\section{Biomed Central}


[9], however, only assessed clustering at the phylogenetic clade level, not individual HPV type level. We, therefore, have investigated this issue in a cross-sectional study of HIV-positive women in Nairobi, Kenya.

\section{Materials and methods}

The study in Kenya has been described in previous publications [10-12]. Briefly, in 2009, 500 HIV-positive women, aged 18-55 years, were enrolled with the primary aim of comparing cervical cancer screening methods. After obtaining a written informed consent, cervical exfoliated cells were successfully collected from 498 women to perform HPV testing, and HPV DNA was assessed using a general GP5+/6+ primer-mediated PCR to detect 44 HPV types with reverse line blot analysis for genotyping [13]. A venous blood sample was taken to measure CD4 count. Type-specific prevalence was described in detail [10]. HPV prevalence is slightly different in the present report [10], because six women who were HPV-positive only according to HPV generic mix probes were excluded. The study protocol was approved by the Ethical Review Committees of the Kenyatta National Hospital, Kenya; the University of Washington, USA; and the International Agency for Research on Cancer, France.

Statistical methods used in the present report have been described in previous publications $[3,5-8,14,15]$. Briefly, a multivariate logistic regression was used to model type-specific HPV positivity. None of the sexual behavior variables collected by the enrollment questionnaire was included in the models because they were not found to be significantly associated with HPV-positivity in a previous analysis [10].

Three models were used. The Basic model included age and specific HPV type prevalence only as covariates. The Adjusted model added CD4 count (as a continuous variable), use of combination antiretroviral therapy (cART) (never, $<2$ years, $\geq 2$ years) and an interaction term between CD4 counts and cART use. This model adjusted for the fact that low CD4 counts were found to be associated with higher HPV positivity and that this association was weaker among women with a prolonged cART use [10]. The Full

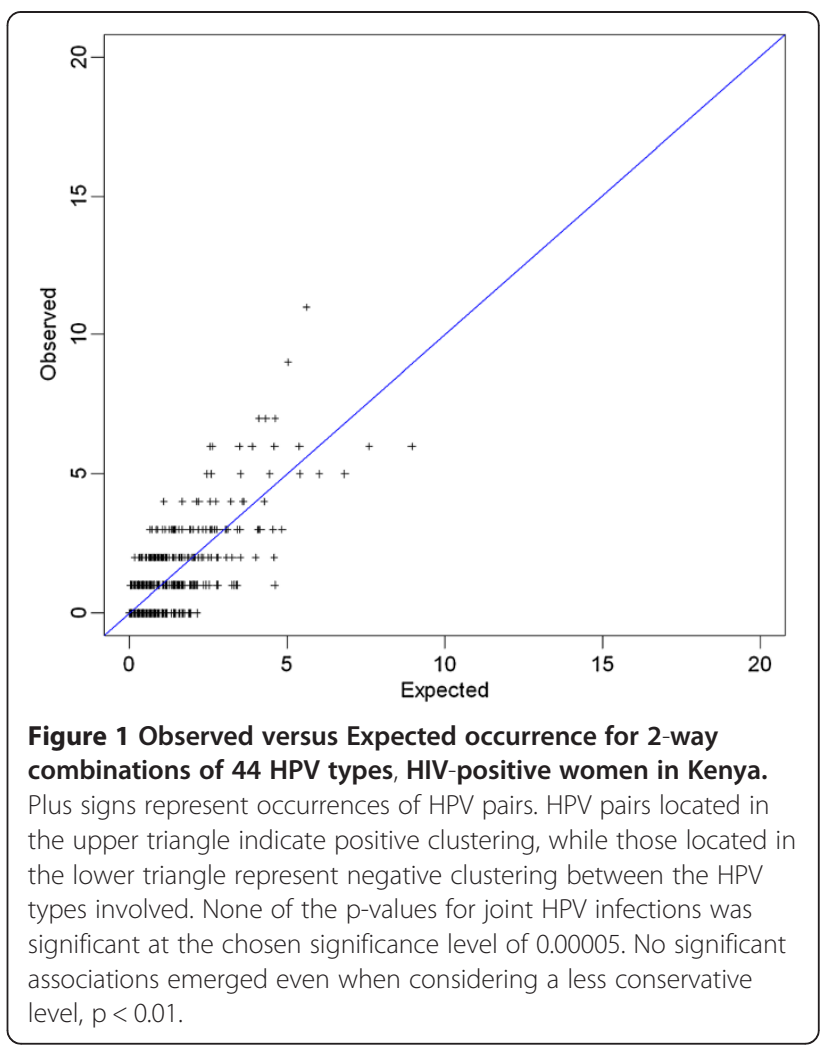

model added individual-level random effects. Random effects quantify and account for the fact that women with several concurrent HPV types may have a higher level of risk for HPV infection compared to women with few or no HPV types, and that type-specific HPV measurements in the same woman are correlated with each other. Individual-level random effects represent unobservable risk factors common to all HPV types [3].

A Bayesian approach with Markov Chain Monte Carlo simulation was used; estimates were reported as posterior means and 95\% credible intervals (95\% CI). Discrepancies between the data (observed counts of co-infections per subject) and the model (expected counts of co-infections per subject) were assessed by posterior predictive two-sided $\mathrm{p}$-values and measured

Table 1 Observed (O) to Expected (E) ratio of multiple infections with $44 \mathrm{HPV}$ types, according to various models

\begin{tabular}{|c|c|c|c|c|c|c|c|c|}
\hline \multirow[b]{2}{*}{ No of HPV types } & \multirow[b]{2}{*}{0} & \multirow[b]{2}{*}{$\%$} & \multicolumn{2}{|c|}{ Basic model } & \multicolumn{2}{|c|}{ Adjusted model } & \multicolumn{2}{|c|}{ Full model } \\
\hline & & & $\mathrm{E}^{1}$ & O/E $(95 \% \mathrm{Cl})^{1}$ & $\mathrm{E}^{2}$ & O/E $(95 \% \mathrm{CI})^{2}$ & $\mathrm{E}^{3}$ & O/E $(95 \% \mathrm{Cl})^{3}$ \\
\hline 0 & 162 & 32.5 & 122.8 & $1.32(1.20-1.46)$ & 131.5 & $1.23(1.11-1.35)$ & 163.1 & $0.99(0.90-1.09)$ \\
\hline 1 & 145 & 29.1 & 175.2 & $0.83(0.81-0.85)$ & 168.7 & $0.86(0.84-0.89)$ & 151.2 & $0.96(0.92-1.00)$ \\
\hline 2 & 103 & 20.7 & 121.4 & $0.85(0.81-0.89)$ & 114.0 & $0.90(0.86-0.96)$ & 92.3 & $1.12(1.03-1.21)$ \\
\hline $3+$ & 88 & 17.7 & 78.6 & $1.13(0.98-1.29)$ & 82.8 & $1.07(0.93-1.22)$ & 90.4 & $0.98(0.87-1.11)$ \\
\hline
\end{tabular}

$\mathrm{O}=$ Observed, $\mathrm{E}=$ Expected, $\mathrm{Cl}=$ Credible Interval.

${ }^{1}$ Controlling for age, specific HPV prevalence.

${ }^{2}$ Controlling for age, specific HPV prevalence, CD4 counts, CART and interaction term between CD4 and CART.

${ }^{3} \mathrm{As}^{2}$ plus individual random effects.

$3+$ means 3 HPV types or more. 
by an observed-to-expected (O/E) ratio for each HPV co-infection. Since all possible two-way interactions between the 44 HPV types were included, this generated $946(44 \times 43 / 2)$ statistical comparisons. To minimize errors due to multiple comparisons, the Bonferroni correction was used to set the p-values thresholds in order to assess statistical significance. With 946 multiple comparisons, the Bonferroni corrected p-value threshold for type-type associations was $0.05 / 946=0.00005$.

\section{Results}

Overall HPV positivity in the 498 HIV-positive women was $67.5 \%(\mathrm{~N}=336)$. Multiple infections were found in $56.8 \%(\mathrm{~N}=191)$ of HPV-positive women (Table 1). According to the Basic model, there was an excess of HPV-negative women $[\mathrm{O} / \mathrm{E}$, ratio $=1.32 ; 95 \%$ Credible Interval (CI): 1.20-1.46]. O/E ratios for infection with 2 and $\geq 3$ HPV types were 0.85 (95\% CI: 0.81-0.89) and 1.13 (95\% CI: 0.98-1.29), respectively. With the Adjusted model, the O/E ratio was 1.23 (95\% CI: 1.11-1.35) for 0 HPV types, 0.90 (95\% CI: 0.86-0.96) for 2 HPV types, and 1.07 (95\% CI: 0.93-1.22) for $\geq 3$ HPV types. Inclusion of CD4 counts, cART use and their interaction in the model slightly reduced the discrepancy between observed and expected counts. When the Full model was used, no substantial difference was found between observed and expected counts, with the exception of a small but significant excess of double HPV infections $(\mathrm{O} / \mathrm{E}$ ratio $=1.12,95 \% \mathrm{CI}: 1.03-1.21)$.

No significant deviations of $\mathrm{O} / \mathrm{E}$ counts were observed for each 2-way combination of 44 HPV types (Figure 1). None of the pairs of HPV types reached the chosen level of significance, $p=0.00005$. No significant excess or deficit of 2-way combinations of types was found when we used a less conservative level of significance $(p=0.01)$ (data not shown). The results of the analyses were substantially similar when women with CIN $2 / 3$ were excluded from the analyses and when stratified by cART use (never; ever) and CD4 count $(<$ or $\geq 350$ cells $/ \mu \mathrm{L}$ ) (data not shown).

\section{Discussion}

The present study of HIV-positive women in Kenya found that there was no evidence of either an excess or a lack of clusters between specific HPV types, even though a slight excess of infections with $2 \mathrm{HPV}$ types was observed even after controlling for all sources of common correlation between HPV types (random effects).

Our study is the first to evaluate clustering patterns of specific HPV types among HIV-positive women in Africa. The assessment of the associations between all the different HPV genotypes requires studies with a high statistical power. The present study was relatively small compared to previous studies in the general population
$[3,5,6,8]$. Small size was, however, partly compensated by the larger number of multiple HPV infections in HIVpositive women.

A strength of our analysis was the inclusion into the logistic regression model of random effects at the individual level that allowed us to account for the unobservable risk factors shared by all HPV types. Non type-specific clustering of HPV types has often been observed in previous studies of HIV-negative women prior to the inclusion of random effects. Non type-specific clustering has generally been explained by a correlation with high-risk sexual behavior as all HPV types are sexually transmitted $[3,5,6,8]$. In our study of HIV-positive women from Kenya, however, multiple HPV infections were associated with the degree of immunosuppression and not with sexual behavior [10]. Immunosuppression diminishes the probability of HPV clearance and increases the risk of HPV reactivation [16]. Random effects, however, contributed substantially to reducing the spurious discrepancy between observed and expected numbers of infections, with the possible exception of double infections.

In conclusion, our present findings confirm in HIVpositive women previous results observed in HIV-negative women, providing further evidence on the lack of clustering between carcinogenic HPV types in either immunocompetent or immunosuppressed women.

\section{Abbreviations}

CART: combination antiretroviral therapy; Cl: Credible Interval; HPV: Human papillomavirus; O/E: Observed-to-expected.

Competing interests

The authors declare that they have no competing interests.

\section{Authors' contributions}

MHC, HDV, NRM and SF conceived and designed the study. SV performed the statistical analyses. MHC, NRM, and SRS contributed to data collection. DAMH performed the HPV testing. All authors contributed to the interpretation of the findings, and SV, HDV and MHC wrote the manuscript. All authors approved the final manuscript.

\section{Acknowledgments}

We thank the research personnel, clinic and laboratory staff, and data management teams in Nairobi, Kenya; Seattle, USA; Amsterdam, The Netherlands; and Lyon, France for their work. We recognize the Coptic Hope Center for Infectious Diseases, Nairobi, Kenya, for their cooperation and our patients for their participation and support.

\section{Funding source}

This work was funded by the Washington Global Health Alliance, the National Institutes of Health (grant number 5K23A1065222-04), a grant from the Bill \& Melinda Gates Foundation (grant number 35537), and from the Fondation de France (grant number 00016673).

\section{Role of the funding source}

The funders had no role in the design of the study; the collection, analysis and interpretation of the data; the decision to submit for publication; or the writing of the manuscript. The views expressed in this publication are those of the authors and not necessarily those of the funders.

\section{Author details}

${ }^{1}$ International Agency for Research on Cancer, 150 cours Albert Thomas, Lyon cedex 08 69372, France. 'Department of Obstetrics and Gynecology, 
Kenyatta National Hospital, P.O. Box 19676, off Ngong Road, Nairobi, Kenya. ${ }^{3}$ Coptic Hospital, P.O. Box 21570, Ngong Road, Nairobi, Kenya. ${ }^{4}$ Department of Pathology, VU University Medical Center (VUMC), Amsterdam, The Netherlands. ${ }^{5}$ Department of Global Health, University of Washington, 325 Ninth Avenue, Box 359909, Seattle, WA 98104, USA. ${ }^{6}$ Department of Medicine, University of Washington, 325 Ninth Avenue, Box 359909, Seattle, WA 98104, USA. ${ }^{7}$ Department of Epidemiology, University of Washington,

325 Ninth Avenue, Box 359909, Seattle, WA 98104, USA.

Received: 31 August 2013 Accepted: 18 November 2013

Published: 19 December 2013

\section{References}

1. Clifford GM, Goncalves MA: Franceschi S, for the HPV and HIV Study Group: human papillomavirus types among women infected with HIV: a meta-analysis. AIDS 2006, 20:2337-2344.

2. De Vuyst H, Lillo F, Broutet N, Smith JS: HIV, human papillomavirus, and cervical neoplasia and cancer in the era of highly active antiretroviral therapy. Eur J Cancer Prev 2008, 17:545-554

3. Vaccarella S, Franceschi S, Snijders PJ, Herrero R, Meijer CJ, Plummer M: Concurrent infection with multiple human papillomavirus types: pooled analysis of the IARC HPV Prevalence Surveys. Cancer Epidemiol Biomarkers Prev 2010, 19:503-510.

4. Chaturvedi A, Katki H, Hildesheim A, Rodriguez AC, Quint W, Schiffman M, Van Doorn LJ, Porras C, Wacholder S, Gonzalez P, Sherman M, Herrero R: Human papillomavirus infection with multiple types: pattern of co-infection and risk of cervical disease. J Infect Dis 2011, 203:910-920.

5. Vaccarella S, Franceschi S, Herrero R, Schiffman M, Rodriguez AC, Hildesheim A, Burk RD, Plummer M: Clustering of multiple human papillomavirus infections in women from a population-based study in Guanacaste, Costa Rica. I Infect Dis 2011, 204:385-390.

6. Carozzi F, Ronco G, Gillio-Tos A, De Marco L, Del Mistro A, Girlando S, Franceschi S, Plummer M, Vaccarella S: Concurrent infections with multiple human papillomavirus (HPV) types in the New Technologies for Cervical Cancer (NTCC) screening study. Eur J Cancer 2012, 48:1633-1637.

7. Vaccarella S, Soderlund-Strand A, Franceschi S, Plummer M, Dillner J: Patterns of human papillomavirus types in multiple infections: an analysis in women and men of the high throughput human papillomavirus monitoring study. Plos One 2013, 8:e71617.

8. Vaccarella S, Plummer M, Franceschi S, Gravitt P, Papenfuss M, Smith D, Villa L, Ponce EL, Giuliano AR: Clustering of human papillomavirus (HPV) types in the male genital tract: the HPV in men (HIM) study. J Infect Dis 2011, 204:1500-1504.

9. Chaturvedi AK, Myers L, Hammons AF, Clark RA, Dunlap K, Kissinger PJ, Hagensee ME: Prevalence and clustering patterns of human papillomavirus genotypes in multiple infections. Cancer Epidemiol Biomarkers Prev 2005, 14:2439-2445.

10. De Vuyst H, Mugo NR, Chung MH, McKenzie KP, Nyongesa-Malava E, Tenet V, Njoroge JW, Sakr SR, Meijer CM, Snijders PJ, Rana FS, Franceschi S: Prevalence and determinants of human papillomavirus infection and cervical lesions in HIV-positive women in Kenya. $\mathrm{Br} J$ Cancer 2012, 107:1624-1630.

11. Chung MH, McKenzie KP, Richardson BA, John-Stewart GC, Coombs RW, De Vuyst H, Njoroge JW, Nyongesa-Malava E, Sakr SR, Mugo NR: Cervical HIV-1 RNA shedding after cryotherapy among HIV-positive women with cervical intraepithelial neoplasia stage 2 or 3. AIDS 2011, 25:1915-1919.

12. Chung MH, McKenzie KP, De Vuyst H, Richardson BA, Rana FS, Pamnani $R$, Njoroge JW, Nyongesa-Malava E, Sakr SR, John-Stewart GC, Mugo NR: Comparing pap smear, via, and hpv cervical cancer screening methods among hiv-positive women by immune status, and antiretroviral therapy. AIDS 2013 [Epub ahead of print].

13. van den Brule AJ, Pol R, Fransen-Daalmeijer N, Schouls LM, Meijer CJ, Snijders PJ: GP5+/6+ PCR followed by reverse line blot analysis enables rapid and high-throughput identification of human papillomavirus genotypes. J Clin Microbiol 2002, 40:779-787.

14. Plummer M, Vaccarella S, Franceschi S: Multiple human papillomavirus infections: the exception or the rule? J Infect Dis 2011, 203:891-893.

15. Vaccarella S, Plummer M, Franceschi S: Reply to Cervantes. J Infect Dis 2011, 204:1816-1817.
16. Strickler HD, Palefsky JM, Shah KV, Anastos K, Klein RS, Minkoff H, Duerr A, Massad LS, Celentano DD, Hall C, Fazzari M, Cu-Uvin S, Bacon M, Schuman P, Levine AM, Durante AJ, Gange S, Melnick S, Burk RD: Human papillomavirus type 16 and immune status in human immunodeficiency virus-seropositive women. J Natl Cancer Inst 2003, 95:1062-1071.

doi:10.1186/1750-9378-8-50

Cite this article as: Vaccarella et al: Clustering patterns of human papillomavirus infections among HIV-positive women in Kenya. Infectious Agents and Cancer 2013 8:50.

\section{Submit your next manuscript to BioMed Central and take full advantage of:}

- Convenient online submission

- Thorough peer review

- No space constraints or color figure charges

- Immediate publication on acceptance

- Inclusion in PubMed, CAS, Scopus and Google Scholar

- Research which is freely available for redistribution

Submit your manuscript at www.biomedcentral.com/submit
C Biomed Central 